\title{
Análisis sociolingüístico del queísmo en el español hablado en Santiago de Chile*
}

\author{
Sociolinguistic analysis of the queísmo in the Spanish spoken in Santiago, Chile
}

\author{
Abelardo San Martín Núñez \\ Universidad de Chile, Facultad de Filosofía y Humanidades, Departamento de Lingüística, \\ Santiago, Chile. Correo electrónico: asmartin@uchile.cl
}

En este artículo se describe el empleo del queísmo en el habla santiaguina, desde el punto de vista sociolingüístico. Para tal propósito, se analizó una muestra estratificada de entrevistas realizadas a 120 hablantes santiaguinos. Los objetivos del estudio consistieron en identificar los factores internos que propiciaban el empleo del queísmo y correlacionarlo con factores sociodemográficos del hablante (sexo, edad y grupo socioeconómico). Los resultados muestran que los contextos que más favorecen el queísmo son la omisión de una preposición requerida delante de un que conjuntivo y en estructuras regidas por verbos pronominales ante un que relativo. Asimismo, los factores sociales más sensibles en la ocurrencia del queísmo fueron el grupo socioeconómico del informante y, de modo muy secundario, su sexo. De este modo, se comprobó que el queísmo es más frecuente en el grupo socioeconómico bajo de la comunidad en estudio, así como en las mujeres del corpus analizado.

Palabras clave: español de Chile, sociolingüística, variación sintáctica, queísmo.

In this article, we described the use of the queísmo in Santiago's speech, from a sociolinguistic point of view. For this purpose, a stratified sample of 120 interviews of Santiago's speakers was analyzed. The objectives of the study were to identify the internal factors that promoted the use of the queísmo and to correlate this use with the informant's sociodemographic factors (gender, age and socioeconomic group). The results show that the contexts that promoted the queísmo are the omission of a required preposition before the word que (conjunction) and que (relative pronoun) in Spanish. Also, the social factors that are mostly related to the use of queísmo are firstly, the socioeconomic group of the speakers and secondly, his gender. Thus, the queísmo is more commonly found in the lower classes of the community under study and in females of the analyzed corpus.

Key words: Chilean Spanish, sociolinguistics, syntactic variation, queísmo.

En este trabajo se sintetizan los resultados más relevantes de una de las secciones de nuestra tesis doctoral inédita, "Variación sintáctica y discursiva en el español hablado en Santiago de Chile. Análisis sociolingüístico del queísmo, el dequeísmo, el discurso referido y los marcadores de reformulación”, dirigida por el Dr. Humberto López Morales y leída en la Universidad de Valladolid. 


\section{INTRODUCCIÓN}

El régimen preposicional, en español, determina que algunos verbos, sustantivos y adjetivos se construyan con una preposición delante de su complemento, ya sea un sintagma nominal, un infinitivo o una cláusula sustantiva subordinada por la conjunción que (cf. RAE y ASALE 2010: 685); asimismo, algunas preposiciones forman parte de locuciones preposicionales o conjuntivas o pueden ser requeridas con ciertos adverbios. Por otro lado, el empleo de una preposición puede ser exigible también ante el pronombre que que introduce cláusulas de relativo. Sin embargo, muchos hablantes usualmente omiten las preposiciones cuando no corresponde, de acuerdo con las reglas de la gramática española, delante de la conjunción o del pronombre que, fenómeno conocido como queísmo, que es censurado por la norma académica ${ }^{1}$. El objetivo general de este artículo -de naturaleza cuantitativa y correlacional- es analizar el empleo del queísmo en una muestra de 120 entrevistas realizadas a informantes santiaguinos. Sus objetivos específicos consisten en: a) determinar qué contextos lingüísticos propician la frecuencia de la variante queísta en dicha muestra y b) correlacionar las frecuencias de las variantes no queísta y queísta con las variables sociodemográficas: sexo, edad y grupo socioeconómico de los informantes. La hipótesis, que aquí someteremos a contrastación empírica, es que tanto los factores internos como los factores externos inciden en el empleo del queísmo.

\section{MARCO CONCEPTUAL}

Gómez Torrego (1999) revisa críticamente las principales fuentes para el estudio del queísmo, con el propósito de caracterizarlo, desde el punto de vista gramatical, en contraste con el dequeísmo. Dicho autor define el queísmo como la "supresión de la preposición de delante de la conjunción que cuando aquella es exigida por algún elemento de la oración" (1999: 2108). Para Gómez Torrego "queísmo" y “dequeísmo" deberían ser considerados como términos neutros que describen esquemas sintácticos en la subordinación. Por otro lado, distingue entre el queísmo "conjuntivo”, que se da en las subordinadas sustantivas, y el "pronominal”, que lo hace en las cláusulas relativas. Asimismo, destaca que el queísmo es un subtipo de “adeísmo”, es decir, de elisión de las preposiciones exigidas por el sistema de la lengua, en general, no solo ante $q u e^{2}$.

En el Esbozo de la gramática de la RAE (1973), la omisión de la preposición de aparece escuetamente mencionada, al comentar algunos ejemplos en las cláusulas de complemento directo. Específicamente, se señala que "En textos clásicos y en la lengua actual poco cuidada se suprime a veces la preposición: Hago cuenta que he hallado en él un tesoro de contento y una mina de pasatiempos (Cervantes, Quijote, I, 6) [...]" (RAE 1973: 522). El Diccionario Panhispánico de Dudas (RAE y ASALE 2005), en cambio, proporciona más información al respecto, en la entrada correspondiente, en la cual define el queísmo como “[...] la supresión indebida de una preposición (generalmente de) delante de la conjunción que, cuando la preposición viene exigida por alguna palabra del enunciado" (s. v. queísmo). La Nueva gramática Manual de RAE y ASALE (2010: 827) entrega una definición muy semejante.

2 Entre las causas posibles del queísmo conjuntivo, Gómez Torrego (1999) señala la redundancia nexual (la presencia de dos nexos subordinantes, desde el punto de vista lingüístico, es poco económica), el influjo de otras lenguas (el español y el portugués tienden a la redundancia nexual, pero no otras lenguas como el francés, el italiano, el catalán y el inglés), la explicación fonético-sintáctica (la eliminación de /d/ por relajación en el discurso espontáneo), la 


\subsection{Los estudios sobre el queísmo en muestras orales}

Rabanales (1974) analizó el empleo del queísmo y el dequeísmo en la norma culta de Santiago de Chile, en primer lugar. Según este autor, el queísmo es la “tendencia a 'omitir' la preposición de delante del que preferentemente gramemático, índice de cláusula con verbo en forma personal [...], cuando la norma 'oficial' hace esperar su presencia" (1974: 415). Por otro lado, Rabanales sostiene que el queísmo y el dequeísmo constituyen tendencias que revelan una inestabilidad normativa, debido al cruce de estructuras parecidas como: espero que venga mañana / tengo la esperanza de que venga mañana > *espero de que venga mañana (dequeísmo) / *tengo la esperanza que venga mañana (queísmo) ${ }^{3}$. Posteriormente, el queísmo y el dequeísmo han sido abordados, en muestras orales de diferentes comunidades de habla española, en conjunto, por Bentivoglio (1976), Arjona (1978 y 1979), McLauchlan (1982), García (1986), Boretti de Macchia (1989), Carbonero (1992), Gómez Molina y Gómez Devís (1995) y Almeida (2009). Por su parte, Bentivoglio y Galué (1998-1999) se refieren al queísmo de modo independiente. Almeida compara los resultados de la mayoría de los estudios sobre queísmo y dequeísmo, a fin de valorar su extensión en Hispanoamérica, y concluye que "a diferencia del dequeísmo, la propagación del queísmo a través de la estructura lingüística parece adquirir un carácter pandialectal" (Almeida 2009: 25). Este autor señala dos posibles motivos para este comportamiento: los procesos de elisión suelen ser más frecuentes y naturales que los de inserción y el peso de la norma estándar no es tan fuerte en el caso del queísmo como en del dequeísmo.

\subsection{Definición de la variable en estudio y criterios analíticos aplicados}

El queísmo es una variable que consiste en la alternancia de dos variantes, esto es, la presencia (no queísmo) o la ausencia (queísmo) de una preposición ante un que (conjuntivo o relativo) cuando es exigida por el sistema de la lengua española, es decir, cuando es gramaticalmente necesaria, por ejemplo, me da la sensación de que no ha venido (no queísmo) / *me da la sensación 0 que no ha venido (queísmo) ${ }^{4}$. Cabe destacar que nuestra definición del queísmo no solo considera la ausencia de de,

analogía (los cruces analógicos entre estructuras) y la ultracorrección (la conciencia de que en algunos casos de que es incorrecto puede motivar la eliminación de de en estructuras en las que sí se requiere).

3 Rabanales destaca el carácter altamente polisémico de la preposición de, en particular, y de las preposiciones, en general, por lo que resulta anodina su presencia o ausencia (1974: 442). También señala la inconsistencia de ambos fenómenos (p. 418), puesto que no solo coexisten en una misma comunidad, sino que también en un mismo individuo. En los casos en que no hay alternancia, predomina claramente el queísmo sobre el dequeísmo, ya que este último rasgo tiene una marcada connotación de vulgaridad entre las personas cultas, según dicho autor.

4 Como es usual en los estudios lingüísticos, en nuestro análisis, la marca * señala que la construcción es agramatical. No obstante, nos parece oportuno insistir en que la noción de agramaticalidad que aquí manejamos se refiere a una inconsistencia, de acuerdo con el sistema de la lengua española, no como una incorrección, con respecto al dictamen de la norma académica. Por otro lado, como bien destacan Bentivoglio y Galué (1998-1999), en estricto rigor, el término queísmo se refiere solo a la variante marcada de una variable que implica un caso de alternancia. Sin embargo, hemos optado por emplear el término queísmo para denominar también a la variable en estudio, ya que es muy frecuente -y hasta usual- asociar la denominación de algunos fenómenos, como el que aquí no ocupa, con su opción o variante marcada. Los alcances del concepto de variable sociolingüística son desarrollados, en detalle, en Silva-Corvalán (2001), López Morales (2004), Blas Arroyo (2005) y Moreno Fernández (2009). 
sino que también la de otras preposiciones. De igual manera, es importante considerar no solo la presencia o la ausencia de la preposición ante un que conjuntivo, sino que también ante un que relativo (cf. Rabanales 1974 y Gómez Torrego 1999). Una de las complejidades del estudio del queísmo y el dequeísmo radica en que en estos fenómenos se produce una intersección dinámica entre el sistema de la lengua, la norma académica y el uso concreto de los hablantes (cf. Coseriu 1982: 106-107). Pese a que en muchos estudios se invoca la norma académica como criterio para delimitar los casos de queísmo, en este estudio, hemos asumido una perspectiva centrada en el sistema de la lengua española como descriptor, prescindiendo del enfoque normativista ${ }^{5}$. Como método de comprobación para determinar la necesidad o no de la preposición se empleará la sustitución de la subordinada sustantiva por un sintagma nominal y, finalmente, por un pronombre neutro ${ }^{6}$.

\section{Metodología}

\subsection{Corpus}

El corpus que servirá de base para nuestro estudio corresponde a 120 entrevistas sociolingüísticas pertenecientes a la muestra de Santiago del corpus del grupo de Estudio Sociolingüístico del Español de Chile $(\mathrm{ESECH})^{7}$. El número de entrevistas antes

\footnotetext{
Gómez Torrego (1999) ha insistido en la necesidad de incorporar una perspectiva sistémica, en el análisis del queísmo y el dequeísmo, que supere un enfoque centrado solo en la norma académica. Sin embargo, dicho autor no es absolutamente consistente en su perspectiva sistémica, como sí lo es Rabanales (1974) quien, pese al empleo del concepto de "norma oficial" en su definición de estas tendencias, en la práctica, es plenamente coherente con una aproximación al queísmo y el dequeísmo, con base en la funcionamiento del sistema lingüístico del español. Esto se evidencia en el tratamiento de antes que/de que y después que/de que, que son consideradas por Gómez Torrego (1999) como alternativas válidas, siguiendo el criterio de la RAE, que al parecer aplica un criterio histórico, ya que en latín dichas locuciones no llevaban preposición: ante quam y post quam. No obstante, Rabanales (1974: 425) considera que la primera de estas alternativas constituye un caso de queísmo, ya que la sustitución por un sintagma nominal le permite comprobar la necesidad de la preposición; por ejemplo, se fue antes de que llegara yo > se fue antes de mi llegada $>$ se fue antes de eso/*se fue antes que llegara yo $>*$ se fue antes mi llegada $>$ *se fue antes eso. Aquí hemos optado por seguir el criterio de Rabanales (1974), ya que en nuestros materiales encontramos casos como los ilustrados en 5, 18 y 19 (cf. 4, más adelante), que -a nuestro parecer- revelan que algunos sujetos de la muestra reconocen, en su intuición lingüística, la necesidad sistémica de la preposición de con las locuciones conjuntivas antes y después.
}

6 Cabe recordar que, en lo sustancial, este método es el que sugiere Rabanales (1974) y, posteriormente, Gómez Torrego (1999). También se utilizará como método la sustitución con una cláusula de infinitivo y la transformación a una oración interrogativa; este último procedimiento es recomendado por el Diccionario Panhispánico de Dudas (RAE y ASALE 2005). El trabajo de Rabanales (1992) ha sido de gran utilidad para la comprensión de un método que, desde el punto de vista de la gramática científica, nos permita delimitar los conceptos de queísmo y de dequeísmo en nuestro estudio. Igualmente, Gómez Torrego (1999) se refiere a una serie de casos dudosos de queísmo conjuntivo o pronominal, los que serán considerados, en términos generales, en nuestro análisis. De modo consecuente con la perspectiva sistémica, mencionada en la nota anterior, en este estudio consideraremos el comportamiento de los complementos correspondientes como criterio objetivo.

$7 \quad$ El ESECH es un grupo de investigación del Departamento de Lingüística de la Facultad de Filosofía y Humanidades de la Universidad de Chile coordinado por nosotros. Las entrevistas fueron realizadas a hablantes santiaguinos, entre 2005 y 2011, por los estudiantes en la asignatura de Sociolingüística de los programas de Licenciatura en Lengua y Literatura Hispánicas y Licenciatura en Lengua y Literatura Inglesas de la Universidad de Chile. En la situación de entrevista, los entrevistadores debían tratar de superar la "paradoja del observador" consiguiendo, de esta forma, una muestra significativa de discurso natural grabado (estilo vernáculo) de hablantes representativos de la comunidad de habla en estudio (Labov 1983). Por lo tanto, se procuró generar un clima de confianza con el objetivo de obtener 
indicado totaliza, aproximadamente, 116 horas de grabación, cuya transcripción fue exhaustivamente revisada, sin exclusión de ninguna de las secciones del instrumento.

\subsection{Población y muestra}

En nuestra investigación se consideró la población constituida por hombres y mujeres de la Región Metropolitana de más de 20 años de edad ${ }^{8}$. El cuestionario se aplicó a una muestra del tipo "muestra por cuotas con afijación uniforme" (López Morales 1994: 58). La muestra, así conformada, comprende un total de 120 entrevistas realizadas a igual número de sujetos, distribuidos como se indica en la Tabla 1 que mostramos a continuación 9 :

Tabla 1. Proporción de sujetos según características sociodemográficas de sexo, edad y grupo socioeconómico

\begin{tabular}{lccccccc}
\hline & \multicolumn{2}{c}{ 20-34 } & \multicolumn{2}{c}{ 35-54 } & \multicolumn{2}{c}{ 55 y más } & \\
\hline & H & M & H & M & H & M & Total \\
Medio alto & 5 & 5 & 5 & 5 & 5 & 5 & $=30$ \\
Medio & 5 & 5 & 5 & 5 & 5 & 5 & $=30$ \\
Medio bajo & 5 & 5 & 5 & 5 & 5 & 5 & $=30$ \\
Bajo & 5 & 5 & 5 & 5 & 5 & 5 & $=30$ \\
& 20 & 20 & 20 & 20 & 20 & 20 & $=120$ \\
\hline
\end{tabular}

el estilo de habla más espontáneo del sujeto. Así, no se descartó la posibilidad de realizar la entrevista a personas cercanas al entrevistador, por ejemplo, familiares o amigos, resguardando, en todos los casos, la congruencia de estatus de los sujetos. También se procuró que la entrevista se realizara en un lugar tranquilo, idealmente, en la casa del informante o en un lugar que no le fuera extraño, a fin de garantizar su comodidad. Además, se optó por lugares sin ruido ambiental. Para mayor detalle, cf. San Martín y Guerrero (2015).

8 Por lo que refiere a los criterios de asignación de estatus de hablante nativo de Santiago de Chile, se aplicaron las siguientes restricciones en la selección de los sujetos: 1) haber nacido y residido en forma ininterrumpida en Santiago, 2) haber nacido y residido en Santiago la mayor parte de sus vidas, salvo por periodos que sumados no superen los cinco años y 3 ) haber residido en forma ininterrumpida en Santiago desde los cinco años de edad.

9 En cuanto al tamaño de la muestra, hemos optado por conformarla con un número de informantes considerado, en general, como suficiente en la bibliografía sociolingüística (cf. Trudgill y Hernández Campoy 2007, s. v. representatividad y López Morales 1994: 52). Por otro lado, cabe precisar que los grupos etarios que hemos considerado apelan a tres momentos vitales de los individuos (Blas Arroyo, 2005) relacionados con el ejercicio de una profesión o actividad específicas: 1) ingreso al mercado laboral (20 a 34 años), 2) desarrollo laboral pleno (35 a 54 años) y 3) cesación de funciones o jubilación (55 años y más). En este sentido, se trabaja con etapas por las que pasa el hablante, que suelen estar vinculadas con la cultura de cada comunidad lingüística. 


\subsection{Procedimiento de estratificación social utilizado}

Para la estratificación de los sujetos que conforman la muestra del estudio, se empleó el sistema de adscripción de estatus social que se basa en la asignación del puntaje -que se indica entre paréntesis- a los informantes, de acuerdo con las siguientes variables: a) nivel educacional (3), b) profesión u ocupación (2) y c) comuna de residencia $(1)^{10}$. A partir de la asignación de los mencionados puntajes, se distinguieron cuatro grupos socioeconómicos, definidos según los rangos siguientes: a) Medio alto (MA): 42 - 36, b) Medio (M): 35 - 27, c) Medio bajo (MB): 26 - 18 y d) Bajo (B): 17 - 6. El intervalo de cada rango responde a la mayor coincidencia con los puntajes que han establecido los estudios sociológicos y de mercado para la clasificación de estratos socioeconómicos, aunque con las debidas adaptaciones, puesto que en esta muestra no se incluyen ni el grupo de la extrema pobreza ni el de la extrema riqueza (San Martín y Guerrero 2015).

\subsection{Procedimiento analítico}

Nuestro análisis del queísmo se concentró tanto en la determinación de los contextos sintácticos en los que se emplea dicha variante con mayor frecuencia, como en la observación de la incidencia de los factores sociodemográficos sexo, edad y grupo socioeconómico de los hablantes en el uso de las variantes no queísta y queísta de la variable analizada. El análisis estadístico atenderá a dos niveles de observación: a) en términos descriptivos, según frecuencias absolutas y porcentajes de frecuencia y b) en términos interpretativos o inferenciales, con base en la comparación entre medias o tendencias centrales ${ }^{11}$. El paquete estadístico al que hemos recurrido para la estadística inferencial es el SPSS (Statistical Package for the Social Sciences), versión 15.0 para Windows, específicamente, la prueba Análisis de varianza ANOVA. En atención a que la distribución de los datos, en algunos casos, pudiera ser anormal, se complementará dicho análisis con su análogo de tipo no paramétrico, esto es, Anova de Kruskal Wallis ${ }^{12}$.

10 La explicación en detalle de dichas variables se encuentra en Prieto (1995-1996), cuya propuesta fue perfeccionada y actualizada con base en los estudios disponibles acerca de la realidad socioeconómica chilena. Cabe precisar que el modelo de nivel socioeconómico fue adaptado de estos estudios de mercado en función de los objetivos que se propone la sociolingüística, que busca definir un perfil más bien sociocultural de la comunidad lingüística en estudio. En consideración a esto, para la estratificación socioeconómica, una de las variables más determinantes fue el nivel educacional y, por esta razón, es la que asigna el mayor puntaje. Asimismo, el nivel de ingresos demuestra muy poca relevancia para los estudios antes mencionados, por ello no fue considerado en la determinación de los perfiles socioeconómicos.

11 Por lo que se refiere a la descripción de los procedimientos estadísticos aplicados, en este trabajo seguimos las sugerencias e indicaciones de Moreno Fernández (1990), López Morales (1994) y Hernández Campoy y Almeida (2005).

12 En ambos casos, el grado de significación se definirá en el $5 \%$, según el cual $\mathrm{p}=<0,05$ será estadísticamente significativo. 


\section{Presentación y ANÁlisis De los Resultados}

En nuestro corpus se identificaron 2397 casos de alternancia de la variable "presencia o ausencia de una preposición ante un que conjuntivo o relativo cuando es gramaticalmente necesaria". De dicho total, 1048/2397 (43,7\%) casos corresponden a la variante no queísta, es decir, a la presencia de la preposición, mientras que 1349/2397 (56,3\%) ocurrencias corresponden a la variante queísta, esto es, a su ausencia. Por consiguiente, el queísmo es relativamente más frecuente en la muestra analizada que el no queísmo, tal como puede apreciarse en el Gráfico 1:

Gráfico 1. Porcentaje de frecuencia de las variantes no queísta y queísta en el corpus

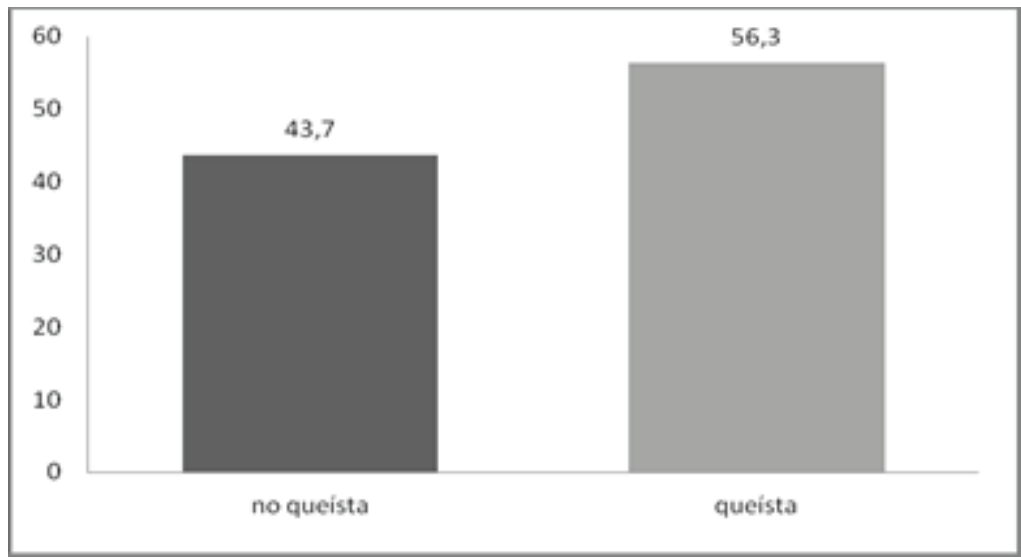

Los siguientes ejemplos ilustran el empleo de la variante no queísta, en nuestros materiales:

1) yo me acuerdo de que cuando cuando llegamos/ sólo habían/ alrededor era puro campo no más/y se veían arrieros/ arriando las vacas/ y vacas comiendo (MIM106) ${ }^{13}$,

2) no dándose cuenta de que el/ si bien tienes el derecho de viajar/ pero no puedes tener el deber/ de de viajar si el el tren está lleno (MAIIIH177),

3) no por el hecho de que tú salgas de la universidad/ inmediatamente tienes comprado el éxito (MIIM121),

4) yo creo que/ a pesar de que me gusta analizar a la gente y sacarle el rollo/ también

3 Respecto de la transcripción de los ejemplos, es necesario señalar las siguientes convenciones gráficas: 1) como se trata de variables no fonéticas y, por lo tanto, la pronunciación no es el foco de nuestro análisis, el texto correspondiente a cada ejemplo se transcribe en ortografía convencional, incluidos los acentos gráficos; 3) con el propósito de no desnaturalizar demasiado la representación del habla chilena, se ha conservado la manifestación gráfica de determinados usos característicos del español hablado en Chile; 4) para la mejor comprensión de los ejemplos incluidos en este estudio, se ha suprimido el sistema de etiquetas que se emplea en la transcripción de las entrevistas, excepto las pausas que se señalan con /. Al final de cada ejemplo, se indica, entre paréntesis, el código del informante, según las siguientes convenciones: grupo socioeconómico $(\mathrm{MA}=$ medio alto, $\mathrm{M}=$ medio, $\mathrm{MB}=$ medio bajo, $\mathrm{B}=$ bajo), grupo etario (III = adultos mayores de 55 años y más, II = sujetos adultos de edad intermedia entre 35 y 54 años y $\mathrm{I}=$ hablantes jóvenes de entre 20 y 34 años $)$ y sexo $(\mathrm{M}=$ mujer y $\mathrm{H}=$ hombre $)$. A continuación del sexo se señala el número correlativo del sujeto en el corpus. 
tengo pocos amigos (MAIH146),

5) yo me casé/ porque después de que nació el G yo me casé (MIIM121),

6) también puede pasar personas que/ con las que puedes pasar mucho tiempo sin verse/ pero la amistad/ sigue intacta (MAIM155).

Por su parte, los siguientes fragmentos ejemplifican el empleo de la variante queísta, en el corpus:

7) un día me acuerdo que yo tuve que salir como a las siete de la tarde/ y tenía que ir/ a ver/ al metro Santa Isabel (BIIM025),

8) como me gusta jugar al arco/ entonces me doy cuenta que ya no no tengo la las aptitudes físicas para poder jugar (MAIIIH180),

9) gente que participa en la farándula y son serios pero a ellos los involucran/ o sea ellos no están convencidos que son/ están metidos en esa mugre de/ de/ de vida que tienen (MBIIIH085),

10) estoy seguro que/ que con algunas personas yo podría contar para alguna cosa en particular (MAIIH165),

11) la movilización está buena/ adonde estoy yo/ a pesar que el Transantiago me jugó una mala pasada un tiempo/ pero ahora está bien (MAIIIH163),

12) tengo amigas de la universidad que me veo hasta el día de hoy (MAIIIM185).

Los ejemplos anteriores reflejan una gran inestabilidad por parte de los hablantes en el empleo de las preposiciones delante de un que conjuntivo o relativo. En general, los casos de queísmo en el corpus corresponden a la omisión de la preposición de, aunque también se dio la ausencia de otras preposiciones como en y con. Una proporción importante corresponde al queísmo relativo, aunque el queísmo conjuntivo también ocupa un lugar preferente en la ocurrencia del fenómeno. Asimismo, mientras los casos de queísmo con la preposición de son de tipo conjuntivo, los queísmos con en son de tipo relativo, por lo tanto, parece haber una relación estructural entre la omisión de ciertas preposiciones y el tipo de queísmo, si bien la omisión de en no es exclusiva del queísmo relativo. Es relevante destacar que, pese a que se trata de fenómenos vinculados, ambos tipos de queísmo obedecen a causas muy distintas: mientras el queísmo conjuntivo se relaciona con el régimen preposicional, el queísmo relativo se enmarca en lo que se ha denominado la "despronominalización" de los relativos (cf. Lope Blanch 1986 y RAE y ASALE 2010), es decir, en la pérdida de su función sintáctica en la cláusula subordinada y su reducción a un simple nexo. Por un lado, se identificaron 1586 casos de alternancia de queísmo conjuntivo, de los cuales $780 / 1586(49,2 \%)$ corresponden a la variante no queísta y 806/1586 (50,8\%) a la queísta; por otro, se encontraron 811 ocurrencias de queísmo relativo, que alternan del siguiente modo: 268/811 (33\%) para la variante no queísta y 543/811 (67\%) para la queísta. Por lo tanto, la incidencia de la variante queísta es mayor en el queísmo relativo que en el conjuntivo, como muestra el Gráfico 2: 
Gráfico 2. Porcentaje de frecuencia de las variantes no queísta y queísta según el tipo de queísmo

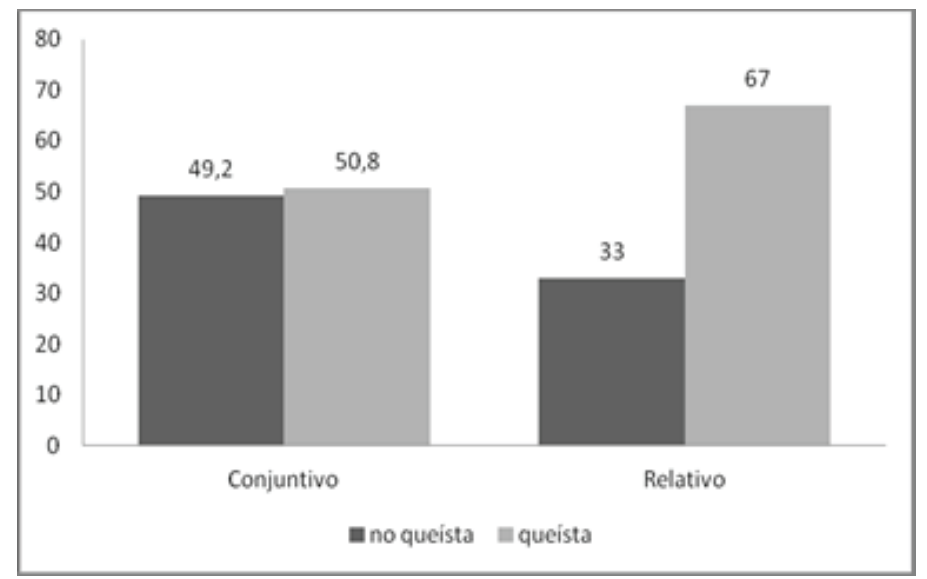

La inestabilidad en el uso preposicional determinó la inexistencia de sujetos plenamente consistentes en el empleo del no queísmo o del queísmo en la muestra. El siguiente ejemplo ilustra la inconsistencia en el uso preposicional delante de que en un mismo sujeto:

13) porque yo me acuerdo de que cuando estaba chica/ me acuerdo que las escarchas que se hacían en las pozas de agua duraban hasta la tarde a veces/ era tanta la helada que caía/ que ahora no llueve tanto/ yo me acuerdo que la cordillera blanca hasta abajo (BIIIM044).

Por otro lado, fue posible determinar la existencia de casos de "adeísmo" (Gómez Torrego 1999), es decir, de omisiones de la preposición regida en contextos en los que no existe un que conjuntivo, lo que también nos parece que es una consecuencia de la inestabilidad en el uso preposicional:

14) me acuerdo una vez que nos fuimos que fue/ al otro día que yo cumplí dieciocho (MAIM157),

15) y/ pucha se dieron cuenta/ el/ el placer que les provocaba/y todo eso po (MBIH049).

De igual modo, en un sentido complementario, pudimos encontrar la presencia de una preposición regida también en contextos en los que no existe un que conjuntivo, como en 16-19:

16) yo no me acuerdo de nada de eso// y que estuvimos en la cueva de Robinson Crusoe y todo eso// pero yo no me acuerdo de nada (MAIIM171),

17) de hecho por eso me preocupo/ de aprender palabras nuevas (MIIH113),

18) con el mismo túnel pero antes de entrar al túnel yo vi una sala donde habían muchas mujeres (MBIIIM089),

19) y después de haber vivido eso mi hermana tuvo un sufrimiento muy grande con su pareja (MBIIIM089). 
De acuerdo con nuestra perspectiva, los ejemplos precedentes evidencian que los sujetos muchas veces reconocen, de modo intuitivo, la necesidad sintáctica del empleo de las preposiciones, en estructuras regidas por categorías sintácticas como los verbos pronominales y no pronominales y los adverbios. Asimismo, aunque se trate de un aspecto tangencial al análisis de la variable en estudio, en nuestro corpus fue posible encontrar casos en los que el pronombre relativo que, al parecer, ha extendido su uso a nuevas funciones sintácticas, lo que, posiblemente, se deba a la profusión de su empleo en ocurrencias queístas. Por una parte, en 20, el pronombre relativo que adquiere un valor posesivo semejante al del pronombre cuyo. Por otra, 21-22 muestran al pronombre que con una función explicativa parecida a la de las conjunciones causales porque o ya que, si bien es posible que se trate del efecto de la elisión del verbo ser en la construcción es que:

20) es un es un/ es como una clínica/ es una clínica privada/ que el dueño de esa clínica es la Universidad de Chile (MAIIIM186),

21) de histerectomía/ se suponía/ de histerectomía// llegué a la clínica// en la noche// que al día siguiente me operaban// y esa noche estaba muy asustada porque la $\mathrm{C}$ era chica (MIIIM141),

22) yo creo que la persona que más me ha dolido perder ha sido mi abuelo// ee/ ese sí yo creo que es la pena más grande que he sentido en mi vida// haber perdido a mi abuelo/ que era una relación muy especial que tenía con él (MIIH115).

\subsection{Factores lingüísticos}

En esta sección, nos referiremos a los factores lingüísticos que propician el empleo del queísmo en la muestra aquí analizada. Se verificó la ocurrencia de la variante queísta en las siguientes estructuras sintácticas: 1) con verbos pronominales y función de complemento de régimen, 2) con verbos no pronominales y función de complemento de régimen, 3) como complemento de sustantivo, 4) como complemento de adjetivo, 5) en locuciones preposicionales, conjuntivas o adverbios, 6) como omisión de otras preposiciones regidas diferentes a de y 7) como omisión de una preposición con que relativo. En la Tabla 2 y el Gráfico 3 se muestran la frecuencia absoluta y porcentual de la ocurrencia del queísmo en las estructuras antes señaladas:

Tabla 2. Frecuencia absoluta y porcentaje de las variantes no queísta y queísta en los contextos identificados en el corpus

\begin{tabular}{lccc}
\hline Contexto & No queísmo & Queísmo & Totales \\
\hline 1) verbos pronominales & $39(13,2)$ & $264(86,8)$ & $304(100)$ \\
\hline 2) verbos no pronominales & $59(85,5)$ & $10(14,5)$ & $69(100)$ \\
\hline 3) sustantivos & $338(60,8)$ & $218(39,2)$ & $556(100)$ \\
\hline 4) adjetivos & $32(49,2)$ & $33(50,8)$ & $65(100)$ \\
\hline 5) locuciones & $166(43,8)$ & $213(56,2)$ & $379(100)$ \\
6) preposiciones diferentes a de & $146(68,2)$ & $68(31,8)$ & $214(100)$ \\
7) que relativo & $268(33)$ & $543(67)$ & $811(100)$ \\
\hline
\end{tabular}


Gráfico 3. Porcentaje de frecuencia de las variantes no queísta y queísta en los contextos identificados en el corpus

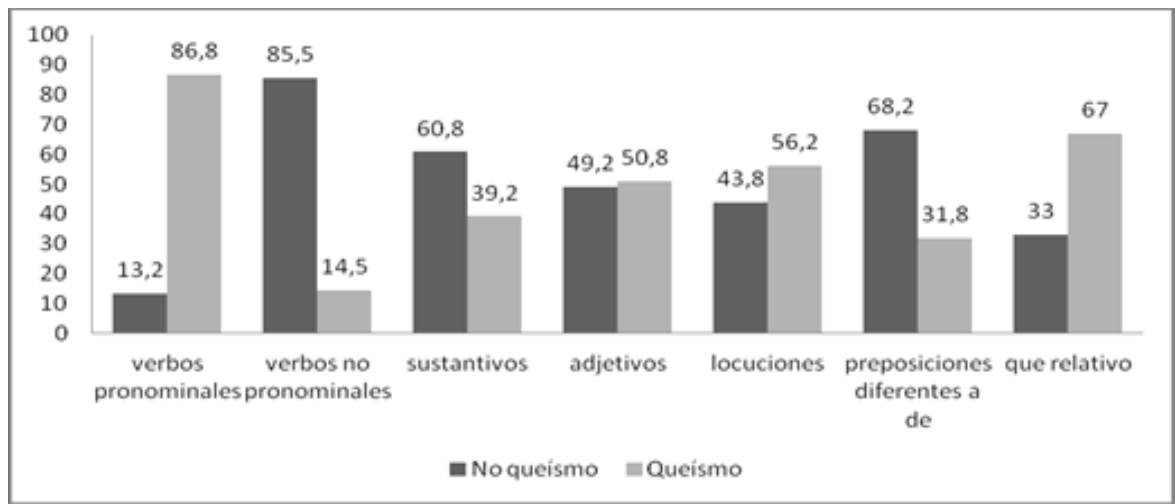

Los contextos lingüísticos que más favorecen la ocurrencia del queísmo, en orden decreciente, son la omisión de la preposición delante de un que conjuntivo en estructuras regidas por verbos pronominales, ante un que relativo, en locuciones preposicionales, conjuntivas o adverbios y en complementos de adjetivo. Por el contrario, la supresión de la preposición delante de un que conjuntivo en estructuras regidas por verbos no pronominales o por sustantivos, así como la omisión de preposiciones diferentes a de parecen no ser las preferidas por los sujetos de la muestra analizada ${ }^{14}$. A continuación, se ejemplificará y explicará cada contexto en que se verificó la incidencia de la variante queísta:

1) Con verbos pronominales y función de complemento de régimen

En la Tabla 3 se muestran la frecuencia absoluta y porcentual de los verbos pronominales más frecuentes (sobre 10 casos) con los que dio queísmo en nuestro corpus:

Tabla 3. Frecuencia absoluta y porcentaje de las variantes no queísta y queísta en verbos pronominales

\begin{tabular}{lccc}
\hline Verbo & No queísmo & Queísmo & Totales \\
\hline acordarse & $12(4,8)$ & $236(95,2)$ & $248(100)$ \\
recordarse & $2(15,4)$ & $11(84,6)$ & $13(100)$ \\
preocuparse & $8(72,7)$ & $3(27,2)$ & $11(100)$ \\
\hline
\end{tabular}

14 Del Valle Rodás (1996-1997) destaca la frecuencia del queísmo con que relativo, mientras Mc Lauchlan (1982), Gómez Molina y Gómez Devís (1995), Bentivoglio y Galué (1998-1999) y Almeida (2009) lo hacen para el queísmo con verbos pronominales. Arjona (1979), Gómez Molina y Gómez Devís (1995) y Almeida (2009) ponen de relieve el queísmo en complementos regidos por sustantivos y Mc Lauchlan (1982) y Bentivoglio y Galué (1998-1999), en locuciones conjuntivas y adverbiales. 
El verbo pronominal que concentra los casos de queísmo es acordarse, seguido a gran distancia por recordarse y preocuparse. Otros verbos como enterarse y olvidarse aportan pocos casos de supresión de la preposición. Esto confirma el carácter sistemático de la ausencia de la preposición de ante un que conjuntivo regida por el verbo acordarse, en el corpus, si bien también da cuenta de su alto empleo por parte de los sujetos, motivado por las preguntas sobre experiencias personales del instrumento. Ejemplos:

23) me acuerdo una vez que nos fuimos que fue/ al otro día que yo cumplí dieciocho/ nos fuimos con seis amigas/a Viña/ porque íbamos al Festival de Viña del Mar (MAIM157),

24) me acuerdo que una vez llegó mi primo así medio pituquito bien arreglado íbamos a un cumpleaños le tiramos un balde lleno de agua (BIH002),

25) yo me recuerdo que también las bolsas cayeron/ hubo mucho alboroto/ también las cosas subieron/ también las tasas de interés subieron (MBIIIM089)

26) la gente se olvidó también que que antes igual tampoco era tan tan bueno (MIH098).

2) Con verbos no pronominales y función de complemento de régimen

De los casos de queísmo con verbos no pronominales, seis corresponden a tratar y cuatro a casos únicos de los verbos convencer, culpar, depender y dudar. Ejemplos:

27) estoy tratando que mi mis labores de oficina mis labores de pega/ de trabajo/ no me quiten/ mi mi mis momentos de esparcimiento/ mis momentos de estar con mis hijos/ mis momentos de estar con la familia o con las personas que quiero (MAIIH163),

28) y después salió con la tremenda casaca de la/ de tienda/ dudo que se la haya comprado/ debió haber sacado etiqueta (BIIM026) ${ }^{16}$.

3) Como complemento de sustantivo

En la Tabla 4 se muestran las frecuencias absoluta y porcentual de los sustantivos más frecuentes con los que se verificó la ocurrencia del queísmo en nuestro corpus:

Tabla 4. Frecuencia absoluta y porcentaje de las variantes no queísta y queísta en sustantivos

\begin{tabular}{lccc}
\hline Sustantivo & No queísmo & Queísmo & Totales \\
\hline cuenta & $28(18,9)$ & $120(81,1)$ & $148(100)$ \\
sentido & $42(73,7)$ & $15(26,3)$ & $57(100)$ \\
hecho & $32(72,7)$ & $12(27,3)$ & $44(100)$ \\
tema & $9(60)$ & $6(40)$ & $15(100)$ \\
\hline
\end{tabular}

\footnotetext{
El verbo pronominal recordarse aparece recogido ya en Rabanales (1974: 428-429), quien señala que es el resultado del cruce entre acordarse y recordar.

16 Con respecto a este último ejemplo, a pesar de que Gómez Torrego (1999: 2117-2118) considera que dudar es un verbo con dos regímenes, bajo el punto de vista que aquí hemos asumido, hemos optado por seguir la interpretación de Rabanales (1974: 425) que lo considera como un caso de queísmo.
} 


\begin{tabular}{llll}
\hline sensación & $6(46,2)$ & $7(53,8)$ & $13(100)$ \\
idea & $7(58,3)$ & $5(41,7)$ & $12(100)$ \\
posibilidad & $6(54,5)$ & $5(45,5)$ & $11(100)$ \\
\hline
\end{tabular}

El sustantivo cuenta es el que predomina -por mucho- en frecuencia en este contexto de ocurrencia del queísmo. Específicamente, se trata de la construcción “darse alguien cuenta de algo", en la que se verificó más de la mitad de las ocurrencias de la variante queísta en esta categoría. Le siguen en importancia los sustantivos sentido y hecho, aunque a una gran distancia de cuenta, así como los sustantivos tema, sensación, idea y posibilidad. Otros sustantivos como problema, punto, temor, duda, impresión, miedo, noticia, riesgo y suerte aportan muy pocos casos. En nuestra opinión, estos datos también confirman el carácter sistemático de la ausencia de la preposición de ante un que conjuntivo exigida por el sustantivo cuenta, en nuestros materiales. Ejemplos:

29) si fui capaz de vivir en un lugar así/ digamos/ ee lo pasé súper bien/ me di cuenta que puedo vivir en cualquier lugar de Chile (MAIIIH180),

30) se puede decir que me gustaba la ideología y me dejé guiar su cierto tiempo por ellos pero/ al final al cabo me di cuenta que no era lo mío ¿cachái? (BIH002),

31) era hermoso/ pero ahora es fome en el sentido que/ claro/ esperamos las doce tomándonos un copete (MIIH117),

32) me encanta el hecho que hay barrios que son como súper top (MAIM157).

4) Como complemento de adjetivo

Se trata de los adjetivos seguro, con 20 ocurrencias; convencido y pendiente, con cuatro casos cada uno y cierto, consciente, culpable, negativo y preocupado con solo una ocurrencia, respectivamente ${ }^{17}$. Ejemplos:

33) yo estoy seguro que la mayoría de esos que no están inscritos ee serían capaces de inscribirse para sacarlo (MAIIIH180),

34) creo que/ es más/ estoy convencida que el matrimonio es una vocación que yo no tengo (MBIIM073).

5) En locuciones preposicionales, conjuntivas o adverbios

La Tabla 5 presenta las frecuencias absoluta y porcentual de las locuciones preposicionales, conjuntivas, o adverbios más frecuentes con que se verificó la presencia de la variante queísta:

7 En los casos de queísmo en los complementos, tanto de adjetivo como de sustantivo, es determinante el verbo de apoyo empleado. 
Tabla 5. Frecuencia absoluta y porcentaje de las variantes no queísta y queísta en locuciones

\begin{tabular}{lccc}
\hline Locución & No queísmo & Queísmo & Totales \\
\hline a pesar & $77(81,1)$ & $18(18,9)$ & $95(100)$ \\
aparte & $8(9,4)$ & $77(90,6)$ & $85(100)$ \\
después & $11(20,8)$ & $42(79,2)$ & $53(100)$ \\
además & $0(0)$ & $40(100)$ & $40(100)$ \\
antes & $7(18,9)$ & $30(81,1)$ & $37(100)$ \\
\hline
\end{tabular}

Las locuciones además y aparte concentran la gran mayoría de los casos de queísmo en este contexto. Le siguen antes y después, aunque notablemente distanciadas de las primeras. A pesar no favorece la ocurrencia del queísmo. Se verificaron tres casos de queísmo con la construcción en caso, mientras otras locuciones presentaron solo una ocurrencia. Ejemplos:

35) yo veo poco// y/ aparte que tengo diabetes// se me está cortando la vista (MBIIM075),

36) fortalecer más las habilidades sociales// considerando además que/ si estamos en este contexto súper tecnologizado (MIIIM121),

37) de alma en pena/ yo te diría que sí cuando antes que falleciera mi papá (BIIM025).

6) Omisión de otras preposiciones regidas diferentes a de

45 ocurrencias de este tipo de queísmo se registraron, en primer lugar, con la preposición en y el verbo pronominal fijarse (28 casos), el sustantivo medida (nueve instancias), el verbo no pronominal insistir (tres casos), el sustantivo fe (dos ocurrencias), así como los verbos no pronominales confiar y sorprender y el sustantivo momento (una instancia cada uno). Se verificaron, asimismo, 12 casos con la preposición $a$ con el verbo pronominal referirse, el no pronominal ir y la locución pese (dos cada uno) y con el verbo acostumbrarse, los adjetivos acostumbrado, atento, obligado, el sustantivo derecho y la locución en tanto (un caso cada uno). Nueve queísmos se dieron con la preposición con para los verbos coincidir (tres casos) y amenazar (dos instancias), así como un caso, respectivamente, con los verbos empezar, encontrarse y sufrir y con la construcción no estar ni ahi $i^{18}$. Finalmente, se registraron dos casos de queísmo con la preposición para con los verbos apretar y llamar (una ocurrencia para cada uno). Ejemplos:

38) fíjate que he tenido la fortuna de haberme hecho amigos profundos después (MAIIM173) $^{19}$,

8 Locución que se emplea, en el español de Chile, para manifestar indiferencia.

19 Respecto del ejemplo 38, Gómez Torrego (1999: 2137-2138) señala que la ausencia de la preposición con el verbo fijarse en imperativo no debería ser considerado como queísmo, ya que esta forma verbal parece haberse lexicalizado, en gran medida. Nuevamente, nos parece que la presencia de la preposición es exigible, desde el punto de vista del sistema lingüístico, y que lo que parece estar fuertemente lexicalizado, en el español de Chile, más bien 
39) a medida que vas creciendo/ vas madurando/ y te vas dando cuenta que tus amigos los vas clasificando y los vas contando con los dedos (MIM108),

40) no necesariamente temas de conversación tanto/ pero me refiero que siempre hay algo/ un vínculo/ una unión/ un poquito más profunda/ más allá de conocerse bien (MIM109),

41) ojalá coincida que yo pueda/ compartir con mis papás en las vacaciones (MIH098).

7) Omisión de preposición con que relativo

Como ya señalamos, la omisión de una preposición delante de un que relativo constituye una de las estructuras sintácticas predominantes en nuestros materiales. Principalmente, se trata de la supresión de la preposición en, aunque también encontramos casos de omisión de las preposiciones con y a. Ejemplos:

42) no sé cómo será ahora/ pero en el tiempo que yo estudiaba/ entregaban una caja/ de metal/ con huesos/ para que uno estudiara huesos en la casa (MAIIH165),

43) los demás están todos en el barrio donde yo vivía antes/ o sea en la población que vivía antes/ en la en la villa (BIIH019),

44) con mi gente que está fuera del país y que soy amiga/ nos llamamos una vez al mes/a conversar (MAIIIM188),

45) hay personas que les gusta eso (MAIIIH181).

\subsection{Factores sociodemográficos}

En esta sección, se exponen los resultados de nuestra indagación con respecto a la relación de la frecuencia de empleo de las variantes no queísta y queísta con las tres variables extralingüísticas consideradas en el análisis: sexo, edad y grupo socioeconómico de los sujetos de la muestra ${ }^{20}$.

\subsubsection{Sexo}

En la Tabla 6 y el Gráfico 4, presentamos las frecuencias absoluta y porcentual de la ocurrencia de no queísmo y queísmo identificadas en el corpus, de acuerdo con el sexo de los sujetos.

Tabla 6. Frecuencia absoluta y porcentaje de las variantes no queísta y queísta en el corpus según el sexo de los sujetos de la muestra

\begin{tabular}{lccc}
\hline Sexo & No queísmo & Queísmo & Totales \\
\hline Hombres & $549(47,2)$ & $614(52,8)$ & $1163(100)$ \\
Mujeres & $499(40,4)$ & $735(59,6)$ & $1234(100)$ \\
\hline
\end{tabular}

es el empleo de la expresión ¿te fijas?, que funciona como marcador interrogativo de control de contacto.

20 Específicamente, nos interesa determinar cómo se distribuye el empleo de las variantes analizadas en la muestra, con relación a los distintos factores extralingüísticos incluidos en el estudio, a efecto de identificar cuál es el factor más influyente. 
Gráfico 4. Porcentaje de frecuencia de las variantes no queísta y queísta en el corpus según el sexo de los sujetos de la muestra

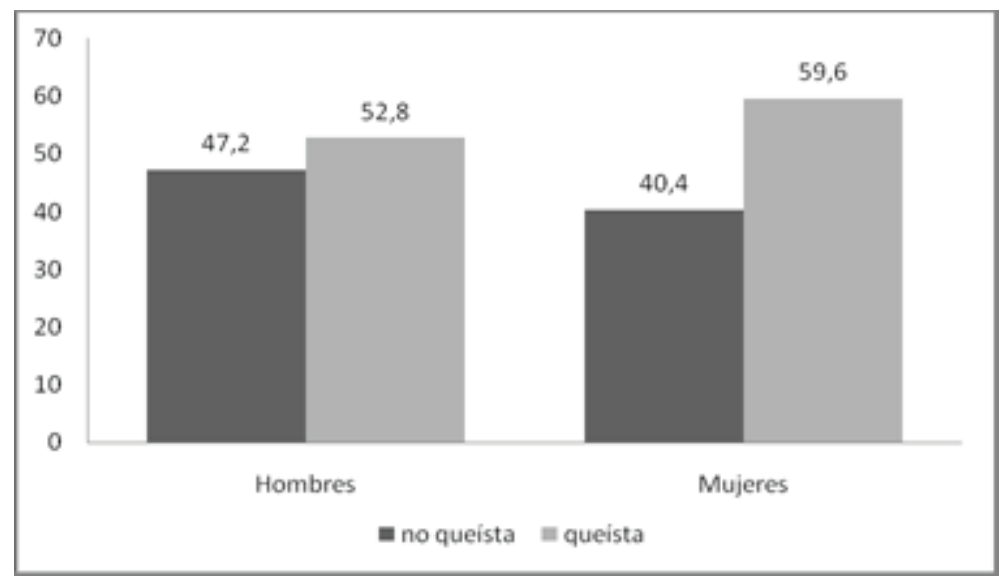

De acuerdo con los datos precedentes, en términos estadísticos descriptivos, el contraste entre las variantes no queísta y queísta es más marcado en las mujeres que en los hombres que conforman la muestra bajo estudio, si bien las diferencias porcentuales no son muy importantes. Según los resultados del análisis paramétrico ANOVA, la media del no queísmo de los hombres es 9,150 y la de las mujeres, 8,317. No obstante, los resultados no son significativos estadísticamente $(\mathrm{F}=0,338, \mathrm{p}=0,562)$. La aplicación de la prueba no paramétrica Anova de Kruskal-Wallis, por su parte, arroja como rangos promedio: hombres $(59,56)$ y mujeres $(61,44)$. Sin embargo, también descarta la significatividad estadística de dichas diferencias, ya que Chicuadrado $=0,088, \mathrm{p}=0,766$. Por consiguiente, en términos estadísticos inferenciales, las diferencias de las frecuencias de la variante no queísta entre hombres y mujeres no es significativa. Por otro lado, el análisis de ANOVA para la ocurrencia del queísmo indica que la media para los hombres es 10,233, mientras que la de las mujeres alcanza a 12,250. Sin embargo, los resultados en este caso tampoco son estadísticamente significativos $(\mathrm{F}=2,903, \mathrm{p}=0,091)$. La aplicación de la prueba no paramétrica no fue necesaria para el queísmo, debido a que los datos se distribuyen normalmente.

\subsubsection{Edad}

La Tabla 7 y el Gráfico 5 muestran las frecuencias absoluta y porcentual de la ocurrencia de las variantes no queísta y queísta identificadas en el corpus, según la edad de los sujetos. 
Tabla 7. Frecuencia absoluta y porcentaje de las variantes no queísta y queísta en el corpus según la edad de los sujetos de la muestra

\begin{tabular}{lccc}
\hline Edad & No queísmo & Queísmo & Totales \\
\hline $\mathbf{2 0 - 3 4}$ & $356(43,8)$ & $456(56,2)$ & $812(100)$ \\
\hline $\mathbf{3 5 - 5 4}$ & $306(40,1)$ & $458(59,9)$ & $764(100)$ \\
$\mathbf{5 5}$ y más & $386(47)$ & $435(53)$ & $821(100)$ \\
\hline
\end{tabular}

Gráfico 5. Porcentaje de frecuencia de las variantes no queísta y queísta en el corpus según la edad de los sujetos de la muestra

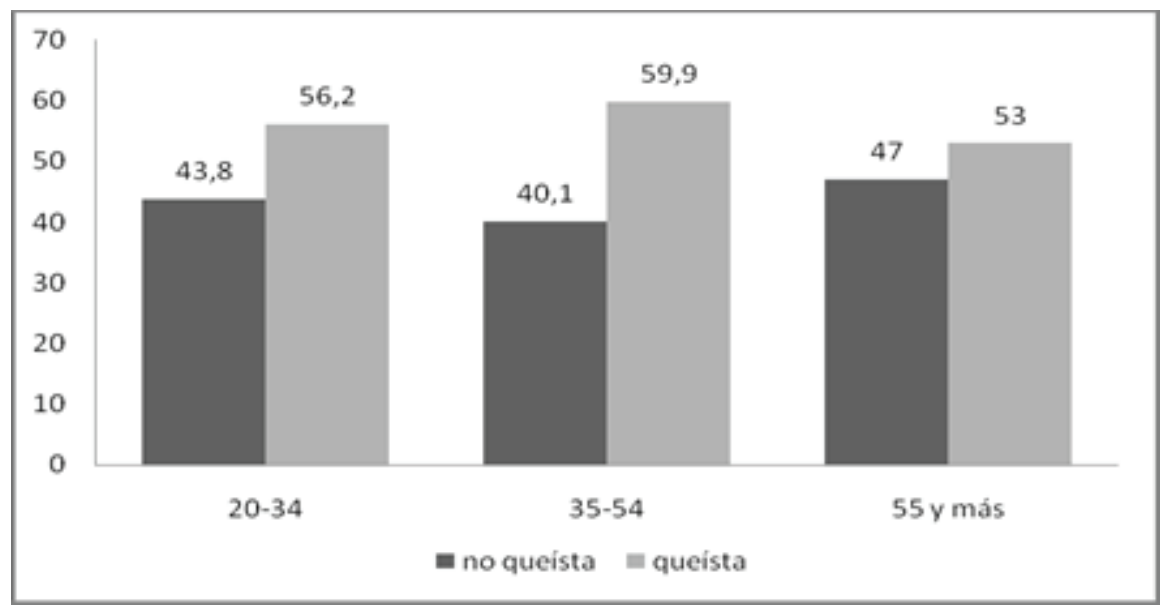

Como se aprecia, descriptivamente, no existen diferencias notables en el empleo de las variantes no queísta y queísta, según los diferentes grupos etarios, aunque existe una mayor distancia entre ambas variantes en el grupo de edad intermedia. Los resultados del análisis ANOVA del no queísmo son los siguientes: 20-34 años $(8,900), 35-54(7,650)$ y 55 y más $(9,650)$. Sin embargo, los resultados no son estadísticamente significativos $(\mathrm{F}=0,662, \mathrm{p}=0,518)$. La prueba no paramétrica, por su parte, da los siguientes rangos promedio: 20-34 años $(62,18), 35-54(57,80), 55$ y más $(61,53)$. No obstante, confirma que estas diferencias no son significativas, puesto que Chi-cuadrado $=0,370, \mathrm{p}=0,831$. Por otro lado, las medias de empleo de la variante queísta son para el primer grupo de 11,400, para el segundo de 11,450 y para el tercero de 10,875, si bien dichas diferencias tampoco son estadísticamente significativas, ya que $\mathrm{F}=0,094, \mathrm{p}=0,911$.

\subsubsection{Grupo socioeconómico}

En la Tabla 8 y el Gráfico 6, se muestran las frecuencias absoluta y porcentual de la ocurrencia de no queísmo y queísmo identificadas en el corpus, según el grupo socioeconómico de los sujetos. 
Tabla 8. Frecuencia absoluta y porcentaje de las variantes no queísta y queísta en el corpus según el grupo socioeconómico de los sujetos de la muestra

\begin{tabular}{lccc}
\hline Grupo & No queísmo & Queísmo & Totales \\
\hline Bajo & $116(32,5)$ & $241(67,5)$ & $357(100)$ \\
Medio Bajo & $226(42,6)$ & $304(57,4)$ & $530(100)$ \\
Medio & $297(43,4)$ & $388(56,6)$ & $685(100)$ \\
Medio alto & $409(49,6)$ & $416(50,4)$ & $825(100)$ \\
\hline
\end{tabular}

Gráfico 6. Porcentaje de frecuencia de las variantes no queísta y queísta en el corpus según el grupo socioeconómico de los sujetos de la muestra.

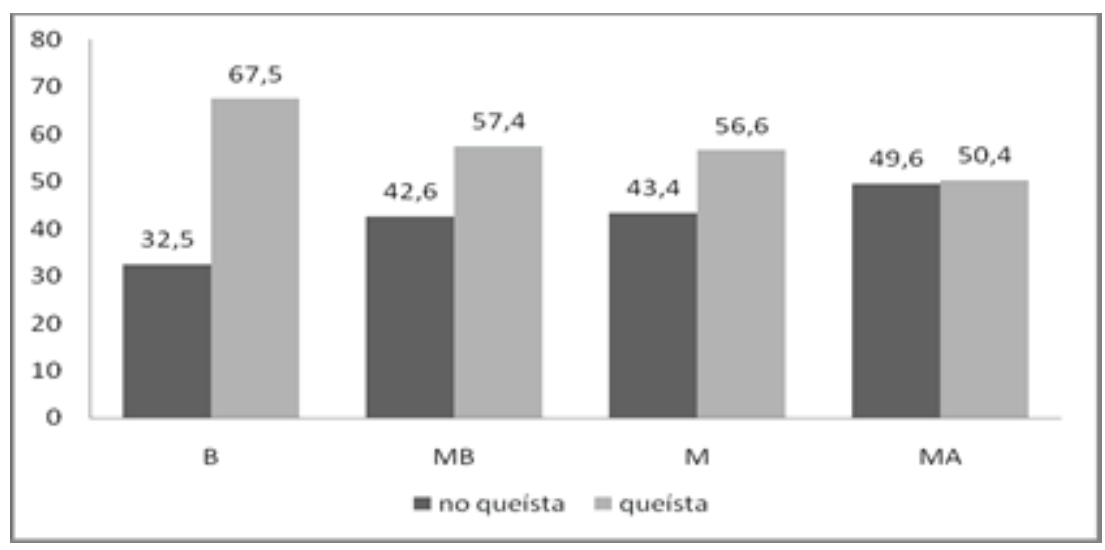

Según nuestros datos, porcentualmente, la ocurrencia de la variante no queísta muestra una curva ascendente desde el grupo bajo hasta el medio alto, la que contrasta con la frecuencia de la variante queísta, que se da en sentido inverso. De este modo, se verifica una mayor distancia entre las frecuencias de ambos valores de la variable en estudio en el grupo bajo, la que va disminuyendo gradualmente hacia el grupo medio alto, donde el no queísmo y el queísmo casi empatan en su porcentaje de ocurrencia. La comparación de las medias del no queísmo, según el grupo socioeconómico, se expone en el Gráfico 7. La prueba ANOVA proporciona los siguientes resultados: bajo $(3,867)$, medio bajo $(7,533)$, medio $(9,900)$ y medio alto $(13,633)$. Asimismo, según dicho procedimiento paramétrico, los resultados son significativos estadísticamente, puesto que $\mathrm{F}=10,129, \mathrm{p}=0,000$. 
Gráfico 7. Medias marginales estimadas de no queísta

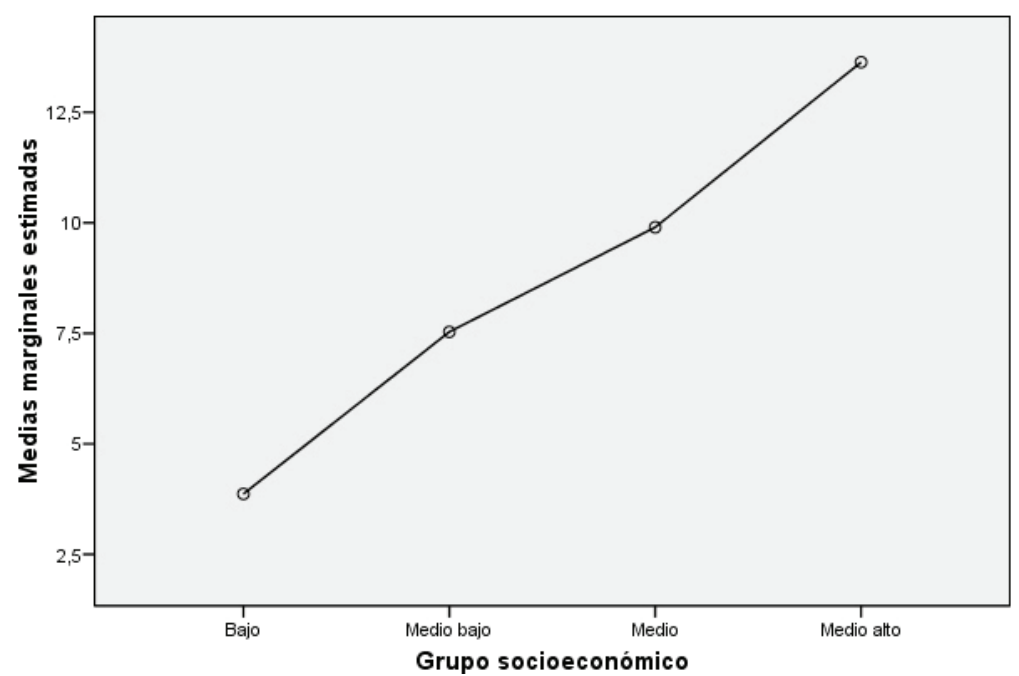

La prueba no paramétrica seleccionada entrega los siguientes rangos promedio: bajo $(35,00)$, medio bajo $(58,00)$, medio $(67,67)$ y medio alto $(81,33)$. Consecuentemente, dicha prueba confirma que estas diferencias son significativas, ya que Chi-cuadrado $=28,428, p=0,000$. Por otro lado, el Gráfico 8 muestra los resultados de la comparación de las medias del queísmo, según los grupos socioeconómicos: bajo $(8,033)$, medio bajo $(10,133)$, medio $(12,933)$ y medio alto $(13,867)$. De igual manera, estas diferencias entre las medias de los grupos son estadísticamente significativas $(\mathrm{F}=5,553, \mathrm{p}=0,001)$.

Gráfico 8. Medias marginales estimadas de queísta

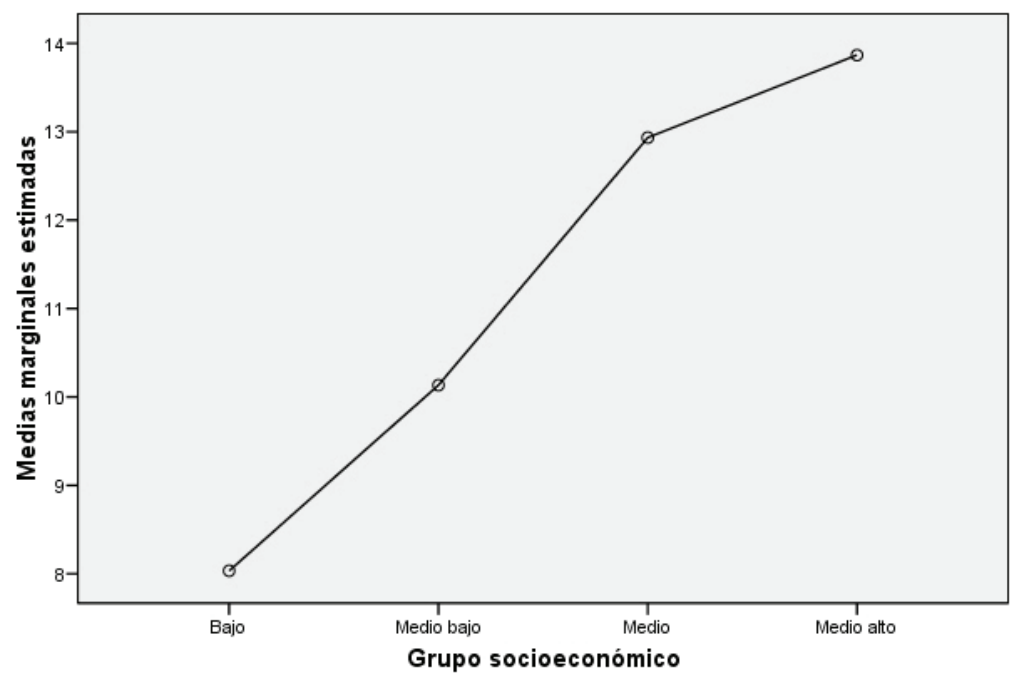


En resumen, desde el punto de vista estadístico inferencial, se comprueba un patrón ascendente desde el grupo bajo hasta el medio alto, para ambos valores de la variable (no queísta y queísta). En este caso, las diferencias se verifican en la forma de la curva que adquiere el patrón antes referido, debido a que su inclinación es más abrupta para el grupo medio en el caso de la variante queísta que respecto de la no queísta. No obstante, lo importante aquí es el contraste de las medias obtenidas, que coincide con el comportamiento representado en el Gráfico 6, en términos de porcentajes, esto es, una mayor distancia entre las medias del no queísmo y el queísmo en el grupo bajo, la que va disminuyendo paulatinamente hasta las del grupo medio alto, donde las diferencias entre ambas variantes son mínimas ${ }^{21}$.

\section{CONCLUSIONES}

Los principales hallazgos de nuestro estudio pueden ser sintetizados del siguiente modo:

1. Se identificaron 2397 instancias de alternancia de la variable "presencia o ausencia de una preposición ante un que conjuntivo o relativo cuando es gramaticalmente necesaria", de los cuales $1048(43,7 \%)$ casos corresponden a su presencia (o variante no queísta) y 1349 (56,3\%), a su ausencia (o variante queísta). Por consiguiente, nuestro análisis evidenció que la ausencia de las preposiciones ante que conjuntivo o relativo supera a su presencia cuando es sintácticamente requerida, en el corpus analizado. En este punto, concordamos con la mayoría de los autores que han analizado este fenómeno, quienes destacan la difusión del queísmo en los dialectos del español (cf. Almeida, 2009).

2. En relación con la incidencia de los factores lingüísticos, en nuestros materiales el queísmo ocurre mayormente como omisión de una preposición delante de un que conjuntivo en estructuras regidas por verbos pronominales $(86,8 \%)$, ante un que relativo (67\%), en locuciones preposicionales, conjuntivas o adverbiales $(56,2 \%)$ y en los complementos regidos por adjetivos $(50,8 \%)$. En los demás contextos, es decir, la omisión en las estructuras regidas por verbos no pronominales (14,5\%), de otras preposiciones diferentes a de $(31,8 \%)$ y en complementos regidos por sustantivos $(39,2 \%)$, el queísmo es mucho menos frecuente. En particular, es más frecuente la omisión de la preposición en ante un que relativo ${ }^{22} \mathrm{y}$ la de la preposición de con el verbo pronominal acordarse, la construcción verbo + sustantivo darse cuenta y los nexos además y aparte.

3. Respecto de la determinación de los factores sociales, la variante queísta se da más -porcentualmente- en mujeres $(59,6 \%)$ que en hombres $(52,8 \%)$, si bien estas diferencias no resultaron ser estadísticamente significativas, por lo que reflejan solo una tendencia en la muestra. Además, no existen diferencias de importancia en la ocurrencia

21 Carbonero (1991), Gómez Molina y Gómez Devís (1995), Bentivoglio y Galué (1998-1999) y Almeida (2009) destacan un mayor empleo del queísmo en las mujeres; sin embargo, del Valle Rodás (1996-1997) indica que se da más en hombres. Boretti de Macchia (1989) y Carbonero (1992) concluyen que no existen diferencias etarias en el empleo de este rasgo. Bentivoglio y Galué (1998-1999) y Almeida (2009) concuerdan en que el queísmo es más frecuente en el grupo social bajo; no obstante, Gómez Molina y Gómez Devís (1995), señalan que se da más en el grupo medio.

22 Es probable que el hecho de que algunos complementos temporales puedan construirse sin preposición en español (p. ej. llegará la próxima semana) influya en la extensión de la omisión de la preposición en ante el pronombre relativo que. 
del queísmo, ni en términos descriptivos ni inferenciales, según los grupos de edad de los sujetos: 20 a $34(56,2 \%), 35$ a $54(59,9 \%)$ y 55 y más años $(53 \%)$. El queísmo se presenta de modo más acusado en el grupo bajo $(67,5 \%)$, manifestando un patrón decreciente con la más baja ocurrencia en el grupo medio alto (50,4\%); entre los grupos medio $(56,6 \%)$ y medio bajo $(57,4 \%)$ se verificó un aumento paulatino. El grupo socioeconómico fue el único factor que resultó significativo estadísticamente en el empleo de esta variable.

4. Por consiguiente, de acuerdo con estos datos, pudimos comprobar nuestra hipótesis sobre el influjo de los factores internos y externos en el empleo del queísmo.

5. En nuestra opinión, en la comunidad de habla santiaguina podría suponerse que el queísmo no carece de cierto prestigio, lo que explicaría su mayor frecuencia en las mujeres, a pesar de que esta última vinculación no mostró ser estadísticamente significativa y de que sí lo resultó la asociación entre la frecuencia del queísmo y el grupo socioeconómico bajo. Si bien se trata de un rasgo no estándar del español, tal vez, se percibe como más correcto elidir la preposición, lo que podría también estar impulsado por un proceso de hipercorrección: los hablantes, quizás, están más conscientes del carácter incorrecto del dequeísmo y, por lo tanto, suprimen una preposición donde no corresponde. Ello supone un relajamiento de la norma lingüística en el español de Chile, aspecto que ya había destacado Rabanales (1974). Asimismo, concordamos con Almeida (2009) respecto de que la elisión de la preposición es más natural que su inserción y podría ser objeto de una valoración positiva.

\section{OBRAS CITADAS}

Almeida, Manuel. 2009. “(De)queísmo y variación sociolingüística en una comunidad urbana canaria”. Revista de Filología 27: 9-30.

Arjona, Marina. 1978. "Anomalías en el uso de la preposición de en el español de México". Anuario de Letras XVII: 67-90.

1979. "Usos anómalos de la preposición de en el habla popular mexicana". Anuario de Letras XVI: 167-184.

Bentivoglio, Paola. 1976. "Queísmo y dequeísmo en el habla culta de Caracas". En Aid, Frances, Melvyn Resnick y Bohdan Saciuk (Eds.), Colloquium on Hispanic Linguistics. Washington: Georgetown University Press. 1-18.

y Dexy Galué. 1998-1999. “Ausencia y presencia de la preposición de ante cláusulas encabezadas por que en el español de Caracas: un análisis variacionista”. Boletín de Filología XXXVII: 139-159.

Blas Arroyo, José Luis. 2005. Sociolingüística del español. Desarrollos y perspectivas en el estudio de la lengua española en contexto social. Madrid: Cátedra.

Boretti de Macchia, Susana. 1989. "(De)queísmo en el habla culta de Rosario". Anuario de Lingüística Hispánica 5: 27-48.

Carbonero, Pedro. 1992. "Queísmo y dequeísmo en el habla culta de Sevilla: análisis contrastado con otras hablas peninsulares y americanas". En Traill, Elizabeth Luna (ed.), Scripta philologica in honorem Juan M. Lope Blanch, II. México: Universidad Nacional Autónoma de México. 43-63.

Coseriu, Eugenio. 1982. "Sistema, norma y habla". En Coseriu, Eugenio, Teoría del lenguaje y lingüística general. Madrid: Gredos. 11-113.

Del Valle Rodás, Juana. 1996-1997. "Para una lingüística interpretativa: (de)queísmo en el habla de Salta”. Anuario de Lingüística Hispánica XII: 797-818. 
García, Erica. 1986. "El fenómeno (de)queísmo desde una perspectiva dinámica del uso de la lengua”. En Moreno de Alba, José (Ed.), Actas del II Congreso Internacional sobre El español de América. México: Universidad Nacional Autónoma de México. 46-65.

Gómez Molina, José y María Begoña Gómez Devís. 1995. "Dequeísmo y queísmo en español hablado de Valencia: Factores lingüísticos y sociales”. Anuario de Lingüística Hispánica XI: 193-220.

Gómez Torrego, Leonardo. 1999. "La variación en las subordinadas sustantivas: dequeísmo y queísmo". En Bosque, Ignacio y Violeta Demonte (Eds.), Gramática descriptiva de la lengua española 2. Las construcciones sintácticas fundamentales. Relaciones temporales, aspectuales y modales. Madrid: Espasa. 2105-2148.

Hernández Campoy, Juan Manuel y Manuel Almeida. 2005. Metodología de la investigación sociolingüística. Málaga: Editorial Comares.

Labov, William. 1983. Modelos sociolingüísticos. Madrid: Cátedra.

Lope Blanch, Juan. 1986. Despronominalización de los relativos. En Estudios de lingüística española. México: UNAM. 119-136.

López Morales, Humberto. 1994. Métodos de investigación lingüística. Salamanca: Ediciones Colegio de España. . 2004. Sociolingüística. Madrid: Gredos.

Mc Lauchlan, Jessica. 1982. "Dequeísmo y queísmo en habla culta de Lima”. Lexis 6 (1): 11-54.

Moreno Fernández, Francisco. 1990. Metodología sociolingüística. Madrid: Editorial Gredos. . 2009. Principios de sociolingüística y sociología del lenguaje. Barcelona: Ariel.

Prieto, Luis. 1995-1996. "Análisis sociolingüístico del dequeísmo en el habla de Santiago de Chile”. Boletín de Filología XXXV: 379-452.

Rabanales, Ambrosio. 1974. "Queísmo y dequeísmo en el español de Chile”. En Tejera, María Josefina (Ed.), Estudios filológicos y lingüisticos. Homenaje a Ángel Rosenblat. Caracas: Instituto Pedagógico. 413-444. 1992. Métodos probatorios en gramática científica. Istmo: Madrid.

RAE (Real Academia Española). 1973. Esbozo de una nueva gramática de la lengua española. Madrid: Espasa Calpe. y ASALE (Asociación de Academias de la Lengua Española). 2005. Diccionario panhispánico de dudas. Madrid: Espasa. 2010. Nueva gramática de la lengua española. Manual. Buenos Aires: Espasa.

San Martín, Abelardo y Silvana Guerrero. 2015. "Estudio Sociolingüístico del Español de Chile (ESECH): recogida y estratificación del corpus de Santiago”. Boletín de Filología L (1): 221-247.

Silva-Corvalán, Carmen. 2001. Sociolingüística y pragmática del español. Washington: Georgetown University Press.

Trudgill, Peter y Juan Manuel Hernández Campoy. 2007. Diccionario de sociolingüística. Madrid: Gredos. 